\title{
Palestinian Prehistory
}

$\mathrm{T}$ HE selection of archæological finds from the caves of the Wady al-Mugharet at the foot of Mt. Carmel, Palestine, now exhibited at the British Museum (see Nature, Feb. 3, p. 169), repays careful inspection. By affording a comprehensive view of the results achieved since 1929 by the Joint Expedition of the British School of Archæology in Jerusalem and the American School of Prehistoric Research under the field direction of Miss D. A. E. Garrod, the exhibit fully confirms previous conclusions, based on the periodical reports, as to the importance of the excavations in these caves, not only for the prehistoric archæology of Palestine, but also for prehistory in general. The discovery of so large a number of skeletons of man of Neanderthaloid type, to whom Sir Arthur Keith would assign generic rank under the name of Palceoanthropus Palestinensis, and including the oldest known complete human skeletons, for which a geological dating as belonging to the Riss-Würm interglaciation is given, would alone place these investigations in the first rank of scientific importance; but in addition they have brought to light a new civilisation and a new race, the Natufian, of late palæolithic or mesolithic age, in which remarkable features of racial character and culture open up suggestive lines of thought in connexion with prehistoric custom and belief and racial distributions.

The exhibits include examples of the small flakes of the Tayacian, comparable with implements from La Micoque, the Upper Acheulean hand-axe, the leaf-shaped point of the Lower Aurignacian, hitherto known only from Africa, Middle Aurignacian scrapers, comparable with those of Western Europe, and characteristic scrapers and gravers from the Upper Aurignacian. The Natufian culture, of which the first evidence was found in the Wady el-Natufa, whence the name, is well represented, among the more striking features being the remarkably elaborate composite head-dresses of shells which were found on the human skeletal remains, and the evidences of the beginnings of agriculture in the form of sickle blades and hafts. The latter are further noteworthy as including among their number two hafts ornamented with carvings of animal heads. These with other gravings on bone or stone are the first and indeed the only known examples of the art of stone age man to be found in Palestine.

The human bones show evidence of cannibalism. Sir Arthur Keith, in reporting on the human remains, judged them to be unique in racial character, but found that certain features suggested affinities with pre-dynastic Egypt. The Natufian faunal remains include the true horse, the Persian fallow-deer and the spotted hyæna, now found only south of the Sahara. The frequent occurrence of remains of the gazelle point to a dry climate and open country, contrasting with conditions in late Mousterian times when the abundant remains of deer suggest a forested area with copious rainfall.

It will thus be seen that the exhibition covers the complete sequence of Palestinian prehistoric cultures from Acheulean to Bronze Age, the last named apparently following on immediately after the Natufian, or, in years, a period ranging from about 100,000 years ago to approximately 6000 B.C.

\section{Future of Artificial Lighting}

$\mathrm{M}^{\mathrm{R}} \mathrm{cov}$ R. C. W. Sully, president of the Illuminating Engineering Society, gave an interesting address at the British Industries Fair at Birmingham on February 22. He pointed out that although great progress has been made in illumination during the past fifty years, yet compared with some other applications of science, such as transport or telephony, its progress appears relatively slow. There is no occupation we can pursue and no recreation we can indulge, in which the eyes are concerned, that does not offer problems in lighting. Too frequently progress takes place in a succession of jerks. As an example, consider the headlights of a motor-car. With increased speed stronger lights were demanded. Concentrated beams, well directed towards the objects requiring illumination, served the driver of the car excellently. But it was soon found out that these beams were a menace to oncoming traffic and glare from headlights is still an outstanding problem.

New devices, new methods and new materials are constantly changing the technique of lighting and developing new sections of industry. The new methods of utilising gaseous tubes producing various colours, the new electric discharge lamps, the continually extending use of stainless steel for reflectors and the applications of the new synthetic plastic materials to lighting fittings may be mentioned. In some cases buildings like cinemas and theatres are expressly designed for use by artificial light. Natural lighting has become a minor matter and is in some cases entirely omitted. In the case of blocks of buildings in congested city areas, access of daylight is imperfect and so costly as to be almost prohibitive.

It is accordingly now being suggested that, in these circumstances, the effort to furnish natural lighting should be abandoned, and that efforts should be concentrated on the provision of adequate artificial lighting. The question arises as to whether there is anything inimical to health in this procedure. This is a question of moment to the lighting industry. The ever-increasing height of buildings and other developments will probably accentuate the need for artificial lighting at the lower levels.

The city of the future has been visualised as consisting mainly of immense flat-topped buildings, rising in terraces from the ground-level, the upper walks being reserved for pedestrians, who would be provided with connecting bridges crossing the roadways at intervals. Roadways at the ground level would be used exclusively for motor traffic. If this is the trend of development, then lighting at the lower levels would be mainly artificial. A suggestion has been made that football, athletic contests and other sports may, in the future, take place in vast covered stadiums where diffused artificial lighting, resembling light from the natural sky, would be attainable and where difficulties arising from our capricious weather would be largely eliminated.

Mr. Sully also discussed the lighting of schools and factories. In school buildings the natural and 